\title{
HEALTH CARE QuALITY REPORTING: A FAILED FoRM OF MANDATED DISCLOSURE?
}

\author{
Kristin Madison*
}

I. The FAILURES OF MANDATED Disclosure .....................315

A. The Troubles of Mandated Disclosure .................... 315

B. The Troubles of Quality Reporting......................... 317

C. The Need to Look Beyond the Troubles .................. 319

II. The Goals of Mandated Disclosure .............................. 321

A. Failure to Do What, Exactly?: The Goals of

Mandated Disclosure................................................ 321

B. The Goals of Quality Reporting.............................. 326

C. The Benefits of Quality Reporting ........................ 329

III. The Costs of MANDATED DisclosuRE .......................... 333

A. The Many Costs of Mandated Disclosure ............. 334

B. The Costs of Quality Reporting........................... 335

C. The Marginal Costs of Quality Reporting............... 338

IV. AlteRnATIVES TO MANDATED DisClOSURE.................... 340

A. Voluntary Reporting as an Alternative to andatory Quality Reporting. 340

B. Direct Regulation as an Alternative to Mandatory

Quality Reporting.. 343

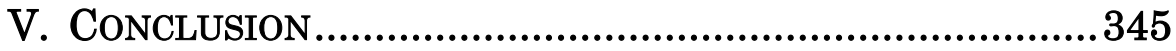

When I received an invitation to participate in a symposium sponsored by the Hall Center for Law and Health and the Indiana Health Law Review, I was delighted to discover that it would include a decision-making and transparency panel. Having written numerous articles discussing law and policy issues related to health care quality reporting, ${ }^{1}$ it seemed obvious that my role on the panel

\footnotetext{
*Professor of Law \& Health Sciences, Northeastern University.

1 See, e.g., Kristin Madison, Regulating Health Care Quality in an Information Age, 40 U.C. DAVIS L. REV. 1577 (2007); Kristin Madison, The Law and Policy of Health Care Quality Reporting, 31 CAMPBELL L. REV. 215 (2009) [hereinafter, Quality Reporting]; Kristin Madison, Legal \&
} 
should be to comment on the influence of quality metrics on patient decision-making. Just two years before, I had published an article that discussed recent trends in health care quality measurement and reporting and offered an optimistic view of how these trends might benefit patients in the future. ${ }^{2}$ The symposium would offer an opportunity to further expand on these thoughts. But the official symposium topic, "medical myths," seemed to point in a different direction. If the goal of the symposium was to encourage challenges to commonly held beliefs, then perhaps I should re-examine my own.

A critical examination of quality reporting as a policy tool seemed particularly appropriate in light of a provocative article $^{3}$ and related recently-published book ${ }^{4}$ proclaiming the failure of mandated disclosure. Surveying the vast landscape of mandated disclosure policies, Professors Omri Ben-Shahar and Carl E. Schneider acknowledge that "mandated disclosure addresses a real problem and rests on a plausible assumption," but argue that "it chronically fails to accomplish its purpose" and that "[e]ven where it seems to succeed, its costs in money, effort, and time generally swamp its benefits." ${ }^{5}$ Quality reporting is one of the many types of disclosure mandates the authors scrutinize. Consumerdirected health care, for example, is a "bounteous fount of mandated disclosure" because it depends on access to reliable information about cost and quality. ${ }^{6}$ Provider report cards are discussed in an article section entitled "The Failures of Other Mandated Disclosures."7

The claim that mandated disclosure is a failure calls into question policy makers' long-standing commitment to public

Policy Issues in Measuring and Improving Quality, in THE OXFORD HaNDBOOK of U.S. HealthCARE LAW (I. Glenn Cohen, Allison K. Hoffman \& William M. Sage eds., March 2016).

${ }^{2}$ Kristin Madison, Donabedian's Legacy: The Future of Health Care Quality Law \& Policy, 10 InD. Health L. REV. 325 (2013).

${ }^{3}$ Omri Ben-Shahar \& Carl E. Schneider, The Failure of Mandated Disclosure, 159 U. PA. L. REV. 647 (2011).

${ }^{4}$ OMri BEN-ShaHAR \& CARL E. SChNEIDER, More Than You WANTED TO KNOW: THE FAILURE OF MANDATED Disclosure (2014).

${ }^{5}$ Ben-Shahar \& Schneider supra note 3, at 651.

${ }^{6}$ Id. at 661.

${ }^{7} \mathrm{Id}$. at $672-74$. 
reporting of provider quality. Was Pennsylvania's 1986 legislation mandating extensive quality reporting pointless or even harmful?' ${ }^{8}$ Was the federal government's 2005 release of hospital quality ratings a waste of time? ${ }^{9}$ Was a 2015 Center for Medicare and Medicaid Services press release announcing an expansion of quality reporting initiatives clearly mistaken when it stated "[t]his large release of quality measures for hospitals and physicians empowers consumers with information to make more informed health care decisions, encourages health care professionals to strive for higher levels of quality, and drives overall health system improvement?"10 Should we abandon the federal website that reveals how often hospital nurses communicated well ${ }^{11}$ and how often surgery patients were given antibiotics at the right time? ${ }^{12}$ Should the federal government decline to publish information about hospital heart attack patient mortality, ${ }^{13}$ nursing home deficiencies, ${ }^{14}$ and nursing home staffing? ${ }^{15}$

It is not entirely clear how Ben-Shahar and Schneider would answer these questions. On one hand, their analysis leaves room for the possibility that quality reporting yields benefits. While emphasizing that mandated disclosure

8 Kristin M. Madison, From HCQIA to the ACA: The Evolution of Reporting as a Quality Improvement Tool, 33 J. LEGAL MED. 63, 73-74 (2012).

${ }^{9}$ Id. at 79 .

${ }^{10}$ Press Release, Ctrs. for Medicare \& Medicaid Servs., CMS Expands Quality Data on Physician Compare and Hospital Compare to Help Consumers Choose Health Care Providers (Dec. 10, 2015) available at https://www.cms.gov/Newsroom/MediaReleaseDatabase/Press-releases/ 2015-Press-releases-items/2015-12-10.html [https://perma.cc/7GGU2KL7].

11 What Information Can I Get About Hospitals?, MediCARE.GOV, https://www.medicare.gov/hospitalcompare/About/Hospital-Info.html [https://perma.cc/H93E-K8JK] (last visited May 26, 2016).

12 Id.

13 Id. Readmissions and Deaths, MEDICARE.GOV https:// www.medicare.gov/hospitalcompare/About/RCD.html [https://perma.cc/ 55UM-XBN8] (last visited May 26, 2016).

14 What Information Can I Get About Nursing Homes?, MEDICARE.GOV, https://www.medicare.gov/NursingHomeCompare/ About/Nursing-Home-Info.html. [https://perma.cc/5RNW-PYL4] (last visited Mar. 3, 2016).

${ }^{15} I d$. 
"routinely fails," they say that it is not doomed to do so, ${ }^{16}$ that "[m]any studies show some improvements" in disclosees' understanding, and that they have "never argued ... that all disclosures fail." 17 In the context of report cards, Ben-Shahar and Schneider acknowledge the existence of "evidence of some success in using disclosures to help people identify superior hospital care."18 On the other hand, frequent health care examples illustrate the many limitations and pitfalls of quality reporting as a policy tool. The authors note that many people do not use report card information. ${ }^{19}$ They reference studies that suggest that quality report cards may produce harmful gaming and ultimately reduce welfare. ${ }^{20}$ The skepticism inherent in their thesis could easily extend to quality reporting.

So should I temper my past optimism about reporting's potential effects? At the risk of being called a "disclosurite," a label Ben-Shahar and Schneider apply to commentators who favor disclosure, ${ }^{21}$ I remain guardedly optimistic. Their work imparts valuable lessons and certainly offers food for thought for disclosurites of all sorts. The book's sensible arguments and voluminous evidence cutting across a broad range of regulatory areas should lead readers to question the advisability of mandated disclosure as a regulatory strategy. At the same time, however, the broad sweep of their work constrains their ability to offer comprehensive assessments of the advisability of particular disclosure policies, leaving readers to wonder whether there are exceptions to the authors' general claim, and if so, what form they might take.

In this essay, I explore the possibility that quality reporting might be just such an exception. I find cause for optimism, in that evidence suggests quality reporting can make a difference. At the same time, however, the exercise reveals just how difficult assessing the success of a particular mandate can be.

16 BEN-SHAHAR \& SCHNEIDER, supra note 4 , at 6.

${ }_{17} I d$. at $47,118$.

${ }^{18} I d$. at 52 . They are also mindful of the possibility that health plans could make good use of report cards; they characterize disclosure to intermediaries as "more sensible than the present system." Id. at 188.

${ }^{19} \mathrm{Id}$. at $64-65$.

${ }^{20} I d$. at $52-53$.

${ }^{21} \mathrm{Id}$. at 6 . 
Part I of this essay explains why Ben-Shahar and Schneider believe that mandated disclosure fails. After conceding that health care quality reporting suffers from many of the problems they have identified, Part I explains why a closer look at the potential impact of health care quality reporting is nonetheless required.

Part II considers the purposes and potential benefits of mandated disclosure. At various points in their book, BenShahar and Schneider offer a quite narrow view of the objectives that disclosure mandates are intended to achieve. In some cases, this view may accurately capture regulators' goals. Part II argues, however, that the policy objectives of governmental quality reporting initiatives are significantly broader than the goal at the heart of Ben-Shahar's and Schneider's analysis. As Professor Richard Craswell has pointed out,22 a multiplicity of goals will inevitably complicate efforts to assess whether a disclosure mandate has succeeded or failed. ${ }^{23}$

Part III examines the costs of mandated disclosure, including both the financial costs of complying with mandates and the costs associated with mandates' unintended effects. It finds that the costs of quality reporting are conceptually challenging to assess because these costs also support other benefit-producing activities. Part III therefore emphasizes the importance of thinking about costs and benefits of disclosure mandates against the backdrop of a broader and ever-changing group of policy interventions.

Part IV briefly considers the question that Ben-Shahar and Schneider leave for the last chapter of their book: what should replace mandated disclosure? They describe ways in which information could reach marketplaces even in the absence of disclosure mandates. They also contemplate the possibility of command-and-control forms of regulation. The points they make are good ones. However, an attempt to apply their analysis to the context of quality reporting shows that the issues involved may be more complex than they first appear.

22 Richard Craswell, Static Versus Dynamic Disclosures, and How Not to Judge Their Success or Failure, 88 WASH. L. REV. 333, 337-40 (2013).

${ }^{23} I d$. 
Part V concludes by calling for the development of a framework that lays out key characteristics of disclosure mandates and the environments in which they operate, so that we can develop a better understanding of the characteristics associated with mandate success.

\section{The Failures of Mandated Disclosure}

In their book, More Than You Wanted to Know: The Failure of Mandated Disclosure, Professors Omri BenShahar and Carl E. Schneider describe many situations in which individuals or entities are legally obligated to disclose some kind of information. ${ }^{24}$ Lenders must provide information about their loans to prospective borrowers; physicians must provide information about treatments to patients; food manufacturers must provide nutrition information; and the list goes on. ${ }^{25}$ Policy makers clearly believe that disclosure mandates can provide some kind of benefit (more on this in Part II). The book's title suggests, however, that mandated disclosure fails. In this Part, I describe the reasoning underlying this claim, and show that many of the troubles that Ben-Shahar and Schneider identify do indeed plague health care quality reporting mandates. I nevertheless argue that it may not be appropriate to classify quality reporting mandates as a "failure," and explain why further analysis is required.

\section{A. The Troubles of Mandated Disclosure}

Ben-Shahar and Schneider lay out their basic claim in the introduction to their book. It is not a claim based on their own empirical research on the effects of the myriad mandates they describe. Instead, they present an argument based on their conception of how disclosure requirements are created and implemented and how the information that flows from requirements is used (or not used): "[m]andated disclosure fails because it depends on a long chain of fragile links. It works only if three actors - lawmakers, disclosers, and

\footnotetext{
24 See BEN-SHAHAR \& SCHNEIDER, supra note 4.

25 See id. at 3-32 (discussing many types of disclosures).
} 
disclosees - play demanding parts deftly." 26 Disclosure requirements must be well-crafted to solve problems that policy makers have accurately diagnosed. ${ }^{27}$ In disclosing data, disclosers must act in ways fully consistent with the well-crafted requirements. ${ }^{28}$ And disclosees must review and fully understand the information provided in order to act appropriately in response to it. ${ }^{29}$ The argument is essentially that broken links lead to failed disclosure. Ultimately, "mandated disclosure seems plausible only on logically reasonable but humanly false assumptions." 30

Ben-Shahar and Schneider support their argument with citations to many studies that provide empirical evidence of broken links. ${ }^{31}$ The authors argue, for example, that individuals are often reluctant to make their own decisions, and may see little value in an extended deliberative process. ${ }^{32}$ Studies show that consumers may devote little time to making a decision, and may reach a decision without making use of available information. ${ }^{33}$ Studies documenting limited levels of literacy and numeracy give reason to doubt that people will understand disclosures. Studies of particular forms of disclosure confirm that such doubts are justified;34 people may "misperceive, misinterpret, and misuse" disclosures. ${ }^{35}$ Information overload may undermine decision-making. ${ }^{36}$ Furthermore, putting information to good use may require background information that people lack. ${ }^{37}$ Studies provide many examples of ways that bounded rationality can lead to poor decision-making. ${ }^{38}$

\footnotetext{
${ }^{26}$ Id. at 7.

${ }_{27} I d$.

$28 I d$.

${ }^{29} I d$. at 8-11.

${ }^{30} I d$. at 10.

31 See Craswell, supra note 22 , at $351-54$ for a description and critique of Ben-Shahar's and Schneider's analytical approach.

32 BEN-SHAHAR \& SCHNEIDER, supra note 4, at 62-64 (reluctance to make decisions); 70-77 (reasons people may choose not to make use of disclosures).

${ }^{33} \mathrm{Id}$. at $64-70$.

${ }^{34} \mathrm{Id}$. at $80-86$.

${ }^{35} \mathrm{Id}$. at 112 .

${ }^{36}$ Id. at $104-106$.

$37 \mathrm{Id}$. at $86-91$.

${ }_{38}$ Id. at $110-12$.
} 
Moreover, disclosures may unduly focus attention in one area, leading disclosees to neglect other areas that may also be important to their decision. ${ }^{39}$ And disclosers may respond in kind, acting in ways that make their mandated disclosures look good, but allowing their performance to deteriorate in areas that are not subject to reporting. ${ }^{40}$ Reporting can lead to changes in behavior that make some intended beneficiaries of the disclosure mandate worse off. ${ }^{41}$

\section{B. The Troubles of Quality Reporting}

Many of the troubles that Ben-Shahar and Schneider aptly describe regularly arise in the world of quality reporting. Indeed, the authors use a number of report cardrelated studies to support their analysis. For example, they cite a study for its finding that relatively few patients sought out comparative information or even considered alternative providers of surgical services. ${ }^{42}$ They cite a study that found that nursing homes improved in areas documented by report cards, but performed less well in other areas. ${ }^{43}$ They cite a classic study showing that when hospital cardiac care report cards were implemented, sicker patients ended up worse off. ${ }^{4}$ This study points to the possibility that entities seeking high scores may alter their conduct in ways that ultimately worsen patient care.

These are just a few of many studies of health care quality reporting that should caution any policy maker or policy analyst who favors quality reporting as a policy strategy. Many patients remain unaware of quality differentials or believe that their current provider is of high quality, so are

${ }^{39} I d$. at 175.

${ }^{40} \mathrm{Id}$. at 176.

${ }^{41} \mathrm{Id}$. at $179-80 ; \mathrm{id}$. at $52-53$.

${ }_{42} I d$. at 65, citing Lisa M. Schwartz et al., How Do Elderly Patients Decide Where to Go for Major Surgery?, 331 BMJ 821 (2005).

43 Id. at 176, citing Susan Feng Lu, Multitasking, Information Disclosures and Product Quality: Evidence from Nursing Homes, $21 \mathrm{~J}$. ECON. MGMT. STRATEGY 673 (2012).

${ }^{44}$ Id. at 179-80 (citing David Dranove et al., Is More Information Better? The Effects of "Report Cards" on Health Care Providers, $111 \mathrm{~J}$. POL. ECON. 555 (2003)). 
not motivated to seek out quality report cards. ${ }^{45}$ Recent studies show that relatively few patients consult ratings. A 2012 survey of internet users found that about $17 \%$ had consulted online rankings or reviews of doctors or other providers, while about $14 \%$ had consulted rankings or reviews of hospitals or medical facilities. ${ }^{46}$ A 2015 poll found that $10 \%$ of respondents had seen comparative quality information about doctors in the past year, and about $61 \%$ of those individuals had used it. About $13 \%$ had seen such information about hospitals, and about $35 \%$ of those individuals had used it. ${ }^{47}$ There are also studies showing that individuals may misinterpret information on report cards. ${ }^{48}$ The federal websites' move toward using quality "stars" and other simplified presentations of data is an acknowledgment of the overly complex nature of previous presentation formats. ${ }^{49}$ And information overload continues to be a problem, although it is not necessarily inherent to government quality reporting mandates. The main problem instead arises from the many competing and sometimes conflicting sources of quality information available through many different websites. ${ }^{50}$

As I have discussed elsewhere, there are also plenty of troubles associated with the content of report cards. ${ }^{51}$

45 See Quality Reporting, supra note 1, at 227.

46 Susannah Fox \& Maeve Duggan, Health Online (2013), available at http://www.pewinternet.org/ /media//Files/Reports/PIP_HealthOnline .pdf [https://perma.cc/9C8L-PRXJ].

${ }^{47}$ Kaiser Health Tracking Poll: April 2015, KAISER FAMILY FOUND. 1213 (Apr. 2015), http://files.kff.org/attachment/topline-methodologykaiser-health-policy-news-index-april-2015 [https://perma.cc/6FYT47D9].

48 See Quality Reporting, supra note 1, at 227, and sources cited therein (exploring difficulties in report card interpretation).

49 See Home Health Star Ratings, CMS.GOV, https://www.cms.gov/ Medicare/Quality-Initiatives-Patient-Assessment-instruments/ HomeHealthQualityInits/HHQIHomeHealthStarRatings.html [https:// perma.cc/F5AV-PUDQ] (last visited May 26, 2016) (explaining reasons for addition of star ratings).

50 See, e.g., Michael B. Rothberg et al., Choosing the Best Hospital: The Limitations of Public Quality Reporting, 27 Health AfF. 1680 (2008), available at http://content.healthaffairs.org/content/27/6/ 1680.full.pdf+html [https://perma.cc/EM3R-7YS5].

51 See Quality Reporting, supra note 1, at 227-36. 
Measure selection is often driven by data availability and other practical considerations, which means that the quality measures reported may not provide the information that consumers care about most. Problems with measure design and data collection can mean that measures fail to reflect true quality. While consumers may be interested in data about individual physicians, the relatively limited number of patients each physician sees presents significant statistical challenges for quality measurement.. Commentators regularly highlight the difficulties in providing accurate information about provider quality. ${ }^{52}$

\section{The Need to Look Beyond the Troubles}

Commentators have pointed out the numerous flaws in quality reporting for many years, ${ }^{53}$ and calls to improve upon quality measurement and reporting initiatives are frequent. ${ }^{54}$ Despite all of these shortcomings, however, I still cling to the possibility that mandated quality reporting might not be a failure.

I confess that my optimism is driven in part by an intuition that Ben-Shahar and Schneider contest: that the somewhat flawed data produced through mandates is better than no data or the bad data that might otherwise fill the information void. It is mostly driven, however, by the belief that some users value the data, coupled with the knowledge

\footnotetext{
52 See, e.g., Steven Findlay, Health Policy Brief: Physician Compare, HEALTH AFF. (Oct. 29, 2015), available at http://healthaffairs.org/ healthpolicybriefs/brief_pdfs/healthpolicybrief_146.pdf [https://perma.cc/ C3X9-N5NL] (describing the challenges in developing the federal physician rating website); Lisa Rosenbaum, Scoring No Goal - Further Adventures in Transparency, 373 NEW ENG. J. MeD. 1385 (2015), available at http://www.nejm.org/doi/pdf/10.1056/NEJMp1510094 [https://perma.cc/48YW-2Z49] (describing statistical limitations involved in assessing physician quality).

53 See, e.g., Timothy Stoltzfus Jost, Oversight of the Quality of Medical Care: Regulation, Management, or the Market?, 37 ARIZ. L. REV. 825, 851-55 (1995) (discussing challenges of creating well-structured report cards).

54 See, e.g., Elizabeth A. McGlynn \& John L. Adams, What Makes a Good Quality Measure?, 312 JAMA 1517 (2014) (calling for creation of "a clear framework and expectations for the intended goals of quality measures").
} 
that quality reporting can sometimes make a difference. More than half of the respondents to a 2015 survey indicated that "[m]aking information comparing the quality of health care provided by doctors and hospitals more available to patients" was a "top priority." 55 Health Affairs articles that have caught my eye include Public Reporting Drove Quality Gains at Nursing Homes ${ }^{56}$ and Public Reporting Helped Drive Quality Improvement in Outpatient Diabetes Care Among Wisconsin Physician Groups. ${ }^{57}$ Other articles with less descriptive titles also suggest that report cards may influence health care delivery. ${ }^{58}$

Perhaps I am overly optimistic about reporting's potential. Given my previous work in this area, I may suffer from confirmation bias. I may accord too much weight to studies finding that report cards have an effect, particularly if journals are more inclined to publish studies showing statistically significant results. But studies like these do give me reason to believe that mandated reporting could at least potentially benefit patients, which raises the question: does it? Or, to be more precise, do the benefits associated with mandated quality reporting exceed its costs?

In their book, Ben-Shahar and Schneider seem to call for investigation of this very question: "[t]he harmlessness hypothesis needs to go; the cost-benefit analysis that has become a norm for regulation should come."59 They do not undertake such an analysis in their book, however. Perhaps they decline to follow through on their suggestion because the broad scope of the book does not allow for detailed

55 Kaiser Health Tracking Poll Topline: April 2015, KAISER FAMILY Found. 6 (Apr. 2015), http://files.kff.org/attachment/toplinemethodology-kaiser-health-policy-news-index-april-2015. [https:// perma.cc/NF55-7X2Z].

56 Rachel Werner et al., Public Reporting Drove Quality Gains at Nursing Homes, 29 HeAlth AFF. 1706 (2010).

${ }^{57}$ Maureen A. Smith et al., Public Reporting Helped Drive Quality Improvement in Outpatient Diabetes Care Among Wisconsin Physician Groups, 31 HEALTH AFF. 570 (2012).

58 See, e.g., M. Kate Bundorf et al., Do Markets Respond to Quality Information? The Case of Fertility Clinics, 28 J. HEALTH ECON. 718 (2009); Justin Wang et al., Do Bad Report Cards Have Consequences? Impacts of Publicly Reported Provider Quality Information on the CABG Market in Pennsylvania, 30 J. Health ECON. 392 (2011).

59 BEN-SHAHAR \& SCHNEIDER, supra note 4, at 182. 
examinations of particular areas of disclosure. Or perhaps they believe that the gains from disclosure are so low, and the costs so high, that careful analysis is not needed to conclude that mandated disclosure is a failure. Or perhaps a full cost-benefit analysis is just not feasible, given the current state of the data.

But even if the data proves to be lacking, a preliminary investigation could help clarify the issues to be addressed in a fuller analysis. In the remainder of this essay, I will describe key benefits and costs of mandated reporting, and explain why I am not yet convinced that mandated quality reporting is a failure, despite all of its troubles.

\section{The Goals of MANDATed Disclosure}

To determine whether any mandate has succeeded or failed, it is important to first clarify what the mandate intended to achieve. In the words of Professor Craswell, "we cannot evaluate the success or failure of any disclosure law without considering the possible goals that law might have had."60 While Professors Ben-Shahar and Schneider acknowledge many potential benefits of properly functioning disclosure laws, much of their analysis implies that policy makers' typical goal in enacting disclosure laws is fully informed decision-making by disclosees. This Part argues that while informed decision-making is surely one goal of quality reporting mandates, it is not the only one, and that any assessment of the impact of quality reporting should take this reality into account.

\section{A. Failure to Do What, Exactly?: The Goals of Mandated Disclosure}

At one level, the goal of mandated disclosure laws is obvious: it is to ensure the availability of the mandated information. But to what end?

Professors Ben-Shahar and Schneider offer one possible answer in the introduction to their book: mandated disclosure "aspires to help people making unfamiliar and complex decisions while dealing with specialists by requiring

${ }^{60}$ Craswell, supra note 22, at 334. 
the latter (disclosers) to give the former (disclosees) information so that disclosees choose sensibly and disclosers do not abuse their position."61 This framing of the issues focuses on the informational advantage that disclosers possess, the possibility that disclosers might exploit this advantage, and the desire to ensure that disclosees make decisions that make sense. Other comments in the book focus more on informing choice than on forestalling exploitation, although clearly the concepts are related. In describing how the success of a disclosure mandate might be assessed, BenShahar and Schneider provide a number of citations that support a view that the "conventional disclosurite understanding" is that a successful mandate will "provid[e] information that equips disclosees to understand their choice well enough that they analyze it and make a well-informed, well-considered decision."62 They suggest that disclosurites often look for "full disclosure."63

Passages scattered throughout the book provide a more nuanced look at the goals of mandated disclosure laws, as illustrated by the writings of a variety of authors. These alternative descriptions of the functions and aims of disclosure mandates are not necessarily inconsistent with an overarching goal of well-considered decisions (or sensible choices). They do, however, focus on different ways that information may be relevant to the decision-making process. For example, in describing the goals of informed consent, Ben-Shahar and Schneider mention the ideas of sovereignty, patient control, and autonomy, in addition to rationality. ${ }^{64}$ They subsequently make a connection between the "autonomy rationale" for disclosure and "dignity," and note that "[s]ome disclosurites believe that giving people disclosures honors disclosees' autonomy whatever its effect on their decisions." 65 In describing the varied functions of different types of mandates, they suggest that "[d]isclosures seek to facilitate, to persuade, and to educate," and that

\footnotetext{
${ }^{61}$ BEN-SHAHAR \& SCHNEIDER, supra note 4 , at 3.

${ }^{62} I d$. at 34 .

${ }^{63} \mathrm{Id}$. at 35 .

64 Id. at $34-35$.

${ }^{65} \mathrm{Id}$. at 36.
} 
"[s]ome disclosures seek more to persuade than inform." 66 Later, in discussing requirements that drug companies disclose payments to physicians, they mention an aim of "accountability."67

This short list of brief passages gives a sense of the considerable challenges of attempting to provide a global assessment of the impact of mandated disclosure laws. If the goal of mandated disclosure is ensuring autonomy, then the question is how much disclosure is necessary to ensure autonomy. If the goal is instead persuasion, then providing full information may not be necessary and may indeed be counterproductive. If the goal is accountability of the discloser, then the question becomes accountability to whom for what, and the focus of the analysis may begin to shift away from the details of the disclosee's decision-making process.

The difficulties of assessing success become even clearer when examining particular mandates. Everyone may agree that the point of nutrition labeling is to provide the information necessary for consumers to choose wisely. But what does this mean? Choosing wisely could mean that consumers weigh the nutritional information along with the price of the food, the taste of the food, and a host of other characteristics in deciding what to eat. This would certainly be consistent with the authors' "well-considered" decisionmaking frame, an orientation toward full disclosure, and the views of many commentators. But the quote the book supplies suggests a different end goal: a reduction in mortality. 68

Full disclosure might be consistent with a mortality reduction goal, and well-considered decisions may help achieve the goal. An evaluation of whether labeling succeeds in reducing mortality might look quite different, however, from an evaluation of the impact labeling has on fullyinformed decision-making. For one thing, if the goals of policy makers and individual consumers do not align, then fully-informed decision-making will not yield the desired results. If consumers place a high value on a tasty diet, a

${ }^{66} I d$. at $28,30$.

$67 \mathrm{Id}$. at 147.

${ }^{68}$ See id. at 39 (quoting from another author's discussion of nutrition labeling). 
study could show that consumers are perfectly informed but that the disclosure mandate is a "failure" from a policy perspective. More importantly, disclosure might reduce mortality even if it falls short of ensuring fully informed decision-making. Labeling might lead to fully informed, wellconsidered decisions that alter consumption patterns and reduce mortality. But it might instead lead to more consumer focus on nutritional quality and somewhat more informed decision-making, which together prod manufacturers to reformulate their products, reducing mortality.

In his essay, Professor Craswell highlights the importance of distinguishing between "static" and "dynamic" disclosures in assessing the success of disclosure mandates. The goal of a static disclosure is to "improve a consumer's choice from among the existing choice set," while the goal of dynamic disclosures "is to improve the existing choice set by creating incentives for sellers to improve the quality of offerings." 69 Craswell's analysis makes clear that the proper approach to assessment will depend on the nature and purpose of the disclosure. To evaluate the success of static disclosures, Craswell suggests examining consumer beliefs; to evaluate the success of dynamic disclosures, Craswell suggests a focus on the average quality of the product in the marketplace. ${ }^{70}$ It may be that one reasonable way of

${ }^{69}$ Craswell, supra note 22, at 334. Under Craswell's model, the goal of static disclosure is to bring the consumer's assessment of quality closer to the true quality, id. at 342, which in turn will ensure that the consumer purchases the right quantity of a particular brand. By contrast, the goal of dynamic disclosure is to "improve the mix of products that is available on the market." Sellers have a proper incentive to improve their product only if changes in consumers' assessment in quality are commensurate with sellers' actual improvement; the goal of dynamic disclosures is thus basically to ensure that sellers get full credit, nothing more, and nothing less, for their improvements. Id. at 343-44. If disclosures achieve perfect information in the marketplace, they will serve both functions, id. at 344, but reality falls short of perfection.

70 Craswell, supra note 22, at 345-350 (assessing static disclosures); id. at 354-72 (assessing dynamic disclosures). As an example of an assessment of dynamic disclosures, Craswell suggests an examination of changes in the relative market shares of high-fat salad dressings and lowfat dressings. Id. at 358-59. Such changes in market share, however, could result from multiple phenomena. First, if most consumers would 
evaluating the success of the informed consent process is by assessing patients' understanding of available treatment options; an evaluation of nutrition labeling may benefit from a different focus.

In sum, Professors Ben-Shahar and Schneider highlight a view that the core goal of mandated disclosure is wellinformed, well-considered decisions, and demonstrate that

prefer to avoid fat but cannot estimate fat content, leading them to buy too many high-fat dressings, ratings that correct misperceptions will increase their purchases of low-fat dressings, while higher-fat dressings remain on the shelf. Second, if consumers accurately estimate fat content but usually ignore it, labeling could draw their attention to this attribute, a phenomenon that would also lead to more purchases of low-fat dressings. In both cases, product mix will change without any manufacturer intervention, although presumably lower levels of consumer demand would eventually lead them to shut down their highfat production lines. Third, in anticipation of increased demand for lowfat products from better-informed or more motivated consumers, producers might reformulate all of their products to be lower in fat, thus increasing market share for low-fat products. Even consumers who pay no attention to fat levels would end up buying low-fat dressings, further boosting low-fat market shares. A fourth possibility is that manufacturers will try to take advantage of consumer attention to salad dressings and their fat content by introducing new products in a way that both expands consumer choice sets and shifts market share toward lowfat products.

I would argue that the first phenomenon seems consistent with Craswell's static disclosure model, while the third is the closest match to the dynamic disclosure model; the second phenomenon seems outside both models, and I am not sure how the fourth is best conceptualized. The effects of all four phenomena, however, are dynamic in nature, since they will ultimately alter product mix in the marketplace.

The difficulty of developing cleanly-defined categorizations of disclosure mechanisms and their effects is apparent in quality reporting as well. The theoretical literature on quality reporting talks about "selection" pathways, where quality increases because patients abandon low-quality providers in favor of higher quality providers, and "change" mechanisms, where quality increases because existing providers improve their own quality. See Damien Contandriopoulos, Francois Champagne \& Jean-Louis Denis, The Multiple Causal Pathways Between Performance Measures' Use and Effects, 71 MED. CaRE RES. AND Rev. 3, 7 (2013) (discussing causal pathways). These scholars observe that "[f]rom a systemic perspective," these two pathways are not always cleanly distinguishable: "the reallocation of resources toward high performers and the eventual closure of underperforming units would probably be construed as change, while, from the perspective of individual units, it amounts to selection." Id. at 8. 
many commentators see full disclosure as ideal. Their book also makes clear, however, that mandated disclosures vary quite widely in nature and content, and can encompass a broader set of functions and goals. In evaluating the success or failure of a disclosure mandate, it is important to consider the benefits that policy makers hope to achieve.

\section{B. The Goals of Quality Reporting}

So what goals might a policy maker who mandates quality reporting seek to achieve, and what are the mechanisms by which reporting may achieve its goals?

In a 2015 press release announcing an update to its health care quality report cards, the Centers for Medicare and Medicaid Services (CMS) explicitly lays out multiple aims: "[t]his large release of quality measures for hospitals and physicians empowers consumers with information to make more informed health care decisions, encourages health care professionals to strive for higher levels of quality, and drives overall health system improvement." 71 The first aim, informed decision making, nicely illustrates the theme that Professors Ben-Shahar and Schneider emphasize. It is consistent with a general goal of ensuring patient autonomy. Patients will be able to understand the choices facing them more clearly, and so may be able to make decisions consistent with their own goals. The CMS formulation does not declare a goal of fully informed decisions, just more informed decisions, which perhaps serves as an implicit acknowledgment of the costs and/or impossibility of achieving a full information ideal.

The second and third aim seem more in line with the dynamic effects that Professor Craswell emphasizes. CMS asserts that quality reporting will alter the effort that providers devote to achieving health care quality; this could be described as an instrumental aim intended to achieve an ultimate goal of boosting quality. And "driv[ing] overall health system improvement" could be described as CMS' overall objective in implementing the quality reporting program. ${ }^{72}$

${ }^{71}$ Press Release, Ctrs. for Medicare \& Medicaid Servs, supra note 10.

${ }^{72} I d$. 
In theory, quality reporting programs could generate a number of desired effects that would culminate in "overall health system improvement." First, the very existence of quality reporting could bring quality issues to consumers' attention. Quality expert David Eddy has suggested that historically, it was assumed that "through the rigors of medical education, followed by continuing education, journals, individual experiences, and exposure to colleagues, each physician always thought the right thoughts and did the right things." 73 If consumers believe that providers think the right thoughts and do the right things, there is little reason for them to seek quality-related information, even if they value quality highly. A survey suggests that many consumers do not believe there are "big differences" in quality across providers. ${ }^{74}$ If consumers believe that "big differences" are the only ones worth looking into, and if in fact there are differences that meet consumers' definitions of "big," then the policy argument for focusing consumers' attention on quality is stronger. In such cases, quality reporting could result in more fully informed decision making that allows consumers to pursue their own quality-related aims.

Second, quality reporting could improve average levels of quality by redirecting the flow of patients to higher quality providers. Patients could visit quality reporting websites and use the available information to select high-quality providers, a mechanism consistent with the basic model that Ben-Shahar and Schneider present. For this mechanism to work, measures must be accurate and consumers must understand and appropriately act on them.

Alternatively, other entities could use the data provided in public quality reports to direct patients to higher-quality providers. For example, an insurer might exclude a poorlyrated provider from a network or provide a financial incentive to the patient to choose a more highly-rated provider. Ben-Shahar and Schneider highlight the potential role that intermediaries might play in ensuring that

${ }^{73}$ David M. Eddy, Evidence-Based Medicine: A Unified Approach, 24 HeALth AFF. 9, 9 (2005).

74 Quality Reporting, supra note 1, at 227 n.61. 
consumers reap the benefit of disclosures, even in the absence of full information. ${ }^{75}$

Third, quality reporting could improve average levels of quality by altering provider behavior. Again, there are several possible mechanisms through which this effect could occur. One is competition: if patients seek matches to more highly-rated providers, and treating patients is profitable, then profit-seeking providers have reason to try to obtain higher ratings. Note that this effect does not depend on the reason for which patients end up at the doorstep of more highly-related providers; all that matters is that they do (or, more precisely, that providers believe they will).

Another possible mechanism through which reporting could alter provider practices is reputation; physicians and hospitals may seek to be recognized for providing higher quality care. ${ }^{76}$ Public reporting could potentially motivate such providers to do better, regardless of the financial consequences that follow from any changes they make. This mechanism requires that public reporting channel information to individuals or entities whose views providers care about; providers might worry about the views of their own patients, but they could also be motivated by information that flows to other providers or to the general public through reporting processes. ${ }^{77}$

Some of these mechanisms require that patients review and understand data, but others do not. Studying whether patients acquire, understand, and use data makes sense if

75 BEN-SHAHAR \& SCHNEIDER, supra note 4, at 188 (discussing intermediaries).

${ }^{76}$ Public reporting could also alter provider practice by supplying information about each provider's own performance as well as the performance of top providers. Providers could use this information to identify areas in need of improvement, to identify other providers potentially worthy of emulation, and to track improvement in the aftermath of efforts to improve quality. I relegate these quality improvement mechanisms to the footnotes because it is mostly quality measurement and private reporting that are important for taking these steps, not public reporting.

77 A third, perhaps less likely mechanism, is that patients may place direct pressure on providers to improve quality. A patient aware of a provider's high infection rates might become especially vigilant about provider handwashing practices, for example. Patients could also become more vigilant about their own handwashing practices, which could also result in better health outcomes. 
one of the goals of information provision is patient autonomy; it also makes sense as an assessment of whether patientbased quality improvement mechanisms have any hope of succeeding. But other tests are also available to determine whether reporting mandates at least have the potential to succeed in improving quality; for example, studies could examine whether providers undertake efforts to improve quality in response to quality rating. And then there is the most direct route to studying whether reporting succeeds in driving improvement: examining the empirical relationship between reporting and quality.

\section{The Benefits of Quality Reporting}

There are actually quite a few studies that have examined quality reporting. They vary considerably in the type of reporting examined, the time period considered, the methodology used, and the overall quality of the analysis. My goal in examining a few of these studies is not to provide a comprehensive review, but instead to convey a sense of the data on which an evaluation of the success or failure of reporting could be based.

As discussed in Part I.B, surveys suggest that some patients use quality data. These same surveys demonstrate, however, that many patients do not. According to the previously mentioned 2015 survey, about six percent of respondents used comparative quality data about physicians. ${ }^{78}$ If the goal is to improve patient autonomy or ensure well-informed decisions, is this finding an indication of success or failure? It's actually hard to say. Some survey respondents might not have had a need for physician care, and so were never faced with a decision about the identity of their provider. Such individuals should surely be excluded from an analysis of whether patients use quality information. Others might have seen a provider, but never even considered the possibility of an alternative provider. It might be argued that these patients should be excluded too, since they did not view themselves as making a decision; alternatively, it might be argued that they should be included, on the grounds that it is important to consider

${ }^{78}$ KAISER FAMILY FOUNDATION, supra note 46, at 13. 
provider quality whenever an individual seeks treatment. Furthermore, even if all individuals are included in the analysis, it could be argued that physician report cards succeeded because they were used by the six percent. There is no obvious place to draw a line between "success" and "failure" when examining a metric like this in isolation;79 what matters most is whether a reporting initiative achieves its ultimate goals.

In short, a few patients actively use report cards, but only a few. If the expectation is that autonomy requires every patient to be fully informed about physician quality at every patient encounter, then reporting could be deemed a failure in this respect. In my view, however, this is not a reasonable standard, and, more importantly, quality improvement, not autonomy, is the primary goal of reporting. From a quality improvement perspective, data suggesting low report card use rates should temper expectations about the impact report cards can have through patient choice-based mechanisms. It is important to look beyond patient survey data, however, to assess the aggregate effect of report cards on care delivery.

Many studies have done just that. 80 Studies examining whether report cards channel patients to higher-quality providers have found mixed results with respect to a variety

79 See Craswell, supra note 22, at 339, 348 (pointing out the indeterminacy of the line between success and failure).

80 See David Dranove, Health Care Markets, Regulators, and Certifiers, in 2 HandBook of Health Econ. 639, 681 (Mark V. Pauly, Thomas G. McGuire, \& Pedro Pita Barros eds., 2012) (summarizing empirical studies of report cards effects); Constance H. Fung et al., Systematic Review: The Evidence That Publishing Patient Care Performance Data Improves Quality of Care, 148 ANNALS INTERNAL MED. 111 (2008) (providing a systematic review of quality report card studies); Dana B. Mukamel et al., Top-Down and Bottom-Up Approaches to Health Care Quality: The Impacts of Regulation and Report Cards, 35 ANN. REV. PUB. HEALTH 477, 486 (2014) (reviewing empirical studies of report cards from 2006 or later); Agency for Healthcare Research and Quality, Executive Summary, Public Reporting as a Quality Improvement Strategy, Closing the Quality Gap: Revisiting the State of the Science, Evidence Report No. 208 (2012), available at https:// effectivehealthcare.ahrq.gov/ehc/products/343/1198/Evidencereport208_ CQG-PublicReporting_ExecutiveSummary_20120724.pdf [https:// perma.cc/4T8L-NH2R] (summarizing results of multiple report card studies). 
of providers, including hospitals, physicians, and nursing homes. Most of these studies do not examine the specific mechanisms for this selection effect, but instead the relationship between reporting and treatment by providers with high quality ratings. For example, one study found that voluntary California bypass surgery report cards increased volume at hospitals with low mortality, ${ }^{81}$ while another found that Pennsylvania's mandated bypass surgery report cards reduced the patient volume of poorly rated surgeons. ${ }^{82} \mathrm{~A}$ study of report cards on fertility clinics found that clinics with higher birth rates obtained larger market shares after report card adoption. ${ }^{83}$ A study examining patient nursing home choice before and after the release of federal nursing home report cards found a statistically significant relationship between reported quality and nursing home choice, but the effect was quite small. ${ }^{84} \mathrm{~A}$ few studies looking at a variety of service types, report cards, and time periods failed to find an effect. ${ }^{85}$ Given the quantity and quality of the studies that do find an effect, however, my conclusion is that it is likely that at least under some conditions, report cards can influence patients' choice of providers.

Recent hospital survey data suggests that providers respond to quality reporting initiatives. One study reports that "[f]or each of the mortality, readmission, process, and patient experience measures, more than $70 \%$ of hospitals agreed with the statement that "public reporting stimulates quality improvement activity at my institution." 86 Furthermore, " $87.1 \%$ of hospitals reported incorporating performance on publicly reported measures into their hospital's annual goals, whereas $90.2 \%$ reported regularly

${ }^{81}$ Patrick S. Romano et.al., Impact of Public Reporting of Coronary Artery Bypass Graft Surgery Performance Data on Market Share, Mortality, and Patient Selection, 49 MED. CARE 1118 (2011).

82 Justin Wang et al., supra note 58, at 392.

${ }^{83} \mathrm{M}$. Kate Bundorf et al., supra note 58.

84 Rachel M Werner et al., Do Consumers Respond to Publicly Reported Quality Information? Evidence form Nursing Homes, $31 \mathrm{~J}$. HEALTH ECON. 50, 59 (2012).

85 See Mukamel et al., supra note 81 at 486 (documenting studies).

${ }^{86}$ Peter K. Lindenauer et al., Attitudes of Hospital Leaders Toward Publicly Reported Measures of Health Care Quality, 174 JAMA INTERNAL MED. 1904, 1907 (2014). 
reviewing the results with the hospital's board of trustees and $94.3 \%$ with senior clinical and administrative leaders." 87 The evidence that public reporting alters hospital behavior is quite robust; this recent evidence adds to a number of other studies that have documented hospitals' responses to quality reporting. 88 Stimulating quality improvement activity, however, is only an intermediate goal of quality reporting; what matters is whether this activity translates into quality improvement.

Studies examining the relationship between report cards and quality have begun to accumulate. As is the case with provider selection studies, these studies do not generally try to isolate the mechanism by which reporting might have an effect, if indeed it does. Findings of these quality studies are mixed, but many studies have found a relationship between reporting and quality, and recent studies seem to have been more likely to find an effect. 89 For example, one empirical study used a differences-in-differences approach to compare treatment outcomes for Pennsylvania hospital patients with those of patients treated at hospitals subject to less intensive or no public reporting; the authors concluded that reductions in mortality were associated with intensive public reporting. ${ }^{90}$ A very recent study using detailed clinical registry data to control for patient risk found that patients who underwent percutaneous coronary interventions (angioplasties) in states with mandated public reporting had lower mortality rates than patients in other states. ${ }^{91}$ Another study found that for "two of three reported. . .

${ }^{87} \mathrm{Id}$.

88 See, e.g., Mark R. Chassin, Achieving and Sustaining Improved Quality: Lessons from New York State and Cardiac Surgery, 21 Health AFF. 40 (2002); Joanne M. Hafner et al., The Perceived Impact of Public Reporting Hospital Performance Data: Interviews with Hospital Staff, 23 INT'L J. FOR QUALITY IN HEALTH CARE 697 (2011); Mukamel et al., supra note 81 , at 487 (discussing recent quality improvement studies).

${ }^{89}$ See Mukamel et al., supra note 81, at 488 (providing broad overview of recent studies).

90 Christopher S. Hollenbeak et al., Reductions in Mortality Associated with Intensive Public Reporting of Hospital Outcomes, 23 AM. J. MED. QUALITY 279 (2008).

${ }^{91}$ Matthew A. Cavender et al., State Mandated Public Reporting and Outcomes of Percutaneous Coronary Intervention in the United States, 115 AM. J. CARDIOLOGY 1494, 1499 (2015). 
measures," postacute care quality rose after the initiation of federal quality reporting. ${ }^{92}$

These studies do not establish that mandated quality reporting is the key to health care system improvement. Relatively few studies have examined physician quality reporting. Some studies, such as the postacute care study just described, find a relationship between reporting and some quality metrics, but not others. When studies do find an impact, its magnitude may be relatively small. For example, a study of federal hospital reporting found no reductions in mortality for heart attack and pneumonia, and only a "modest reduction" for heart failure. ${ }^{93}$

As with the empirical evidence on provider selection, the prevalence of studies finding a connection between reporting and quality metrics suggests that reporting can make a difference, and so mandated quality reporting is not a failure in that sense. The universe of studies leaves open questions about how much of a difference, and the conditions under which report cards are most likely to succeed. Understanding the magnitude of quality benefits (as well as any benefits associated with autonomy or other aims) is important, given the costs associated with reporting.

\section{The Costs of MANDATED Disclosure}

As Part II makes clear, there has been significant effort devoted to thinking about the potential benefits of mandated disclosure, including in the context of quality reporting. This focus makes sense; there is no reason to pursue any regulatory initiative, including reporting mandates, if it yields no cognizable benefits. But if reporting initiatives plausibly meet that threshold, then the next question must be whether the benefits exceed the costs. There seem to be many fewer studies focusing on the costs of disclosure. Some kinds of costs are difficult to calculate for conceptual reasons;

\footnotetext{
92 Rachel M. Werner et al., Impact of Public Reporting on Quality of Postacute Care, 44 Health SeRvs. Res. 1169, 1169 (2009).

${ }_{93}$ Andrew M. Ryan et. al., Medicare's Public Reporting Initiative on Hospital Quality Had Modest or No Impact on Mortality from Three Key Conditions, 31 HeAlTh AFF. 585, 588-90 (2012) (finding in an analysis adjusted for patient characteristics and time trends, a .97 relative risk ratio for heart failure-related mortality).
} 
other kinds of costs are more straightforward, but are not as accessible to researchers as the kinds of data used for Part II's studies. Nevertheless, it is important to at least acknowledge the costs associated with disclosure mandates, including quality reporting.

\section{A. The Many Costs of Mandated Disclosure}

In a chapter entitled, "At Worst, Harmless?," Professors Ben-Shahar and Schneider describe harms that could arise from mandated disclosure. There are many, and they are right to remind disclosure advocates that the costs of disclosure mandates are real, just as they are for other types of mandates. For the regulated entity, costs include those associated with collecting data, preparing disclosure content, disseminating information, and possibly documenting the provision and receipt of the disclosure. ${ }^{94}$ Disclosees' costs include the costs associated with reading disclosures..$^{95}$ I would add that the regulators who design and enforce disclosure mandates may also devote considerable resources to this effort.

But Ben-Shahar and Schneider also recognize that costs extend far beyond those associated with creating and implementing a mandate. They explain that "mandates can undercut other regulation, deter lawmakers from adopting better regulation, impair decisions, injure markets, exacerbate inequality, and in some important cases, cripple valuable enterprises." 96 While all of these effects are illustrated with examples, some seem more broadly applicable than others; I will focus on a few potential costs that seem to have special relevance to quality reporting.

One such cost is "impair[ed] decisions." Ben-Shahar and Schneider note that information supplied could be wrong or direct disclosees' attention away from other things that matter; an overabundance of information could obscure the points that matter most and undermine the value of reporting. ${ }^{97}$ Another cost is directing disclosers' attention

\footnotetext{
${ }^{94}$ BEN-SHAHAR \& SCHNEIDER, supra note 4, at 169-70.

${ }^{95} \mathrm{Id}$. at 170.

96 Id. at 169 .

${ }_{97} I d$. at $175-76$.
} 
away from other things that might matter, but are not subject to reporting. Ben-Shahar and Schneider classify this cost as "making markets worse."98 A third cost is "exacerbating inequality," which can occur if the costs of disclosure mandates are borne by all, but it is the besteducated and, in some cases, the most economically advantaged, who are best positioned to make full use of them. ${ }^{99}$

\section{B. The Costs of Quality Reporting}

The costs associated with mandated health care quality reporting are significant. While the costs of disclosing relevant data are not likely to be especially high in this age of web-based data dissemination, the costs of collecting and reporting the required data can be large. To get a sense of these costs, consider a recent study of cardiology, orthopedics, primary care, and multispecialty practices that concluded that United States physician practices collectively spend more than $\$ 15.4$ billion per year on quality reporting. 100 Or consider the 2015 final rule addressing Medicare's Hospital Inpatient Quality Reporting program. 101 The regulatory impact analysis indicates that by removing certain measures from the previous reporting program, the final rule will reduce the "burden associated with the collection of chart-abstracted data."102 How much? It estimates that removing nine measures will reduce the total burden across all hospitals by 741,000 hours. ${ }^{103}$ The analysis also estimates that for each of the 3,300 hospitals impacted, the "burden per hospital for previously finalized requirements" was 1,135 hours for "chart-abstracted and

98 Id. at 176.

${ }^{99} \mathrm{Id}$. at $178-80$.

${ }^{100}$ Lawrence P. Casalino et al., U.S. Physician Practices Spend More Than \$15.4 Billion Annually to Report Quality Measures, 35 HeALth AFF. 401, 401 (2016) (summarizing results), id. at 402 (describing groups surveyed).

101 Medicare Program, 80 Fed. Reg. 49,326 (Aug. 17, 2015) (to be codified at 42 C.F.R. pt. 412 ).

102 Id. at 49,837 .

$103 \mathrm{Id}$. 
structural measures, forms" and "review[ing] reports for claims-based measures."104

Quality reporting also implicates many of the other kinds of costs on the list offered by Ben-Shahar and Schneider. The risk that poorly-executed report cards could mislead users is real. The data underlying report card metrics could be incorrect, or the metrics themselves could be poor reflections of true quality. Correct metrics could be misinterpreted or misused; for example, findings of one study suggested that giving patients information about provider cost in the hope of promoting high-value care could yield unexpected results, because some patients equate higher cost with higher quality. 105 The provision of ratings related to some dimensions of quality, but not others, could lead patients to unduly focus on those dimensions in making their decisions. Patients checking out Medicare's hospital comparison site by clicking through the tabs presenting different types of quality ratings will first see ratings based on patients' experiences; if they do not click through the rest of the tabs, they may not take into account clinical quality measures such as complication rates or mortality in making their decisions. ${ }^{106}$

Even if patients make good use of report cards, the incentive effects associated with quality reporting could make care worse. Ben-Shahar and Schneider cite research suggesting that nursing homes performed better on measures captured in public reporting, but did worse on others; 107 if providers neglect unmeasured areas, average quality may go down, and quality metrics could mislead report card users. Poorly-constructed measures can have unintended consequences; a metric designed to capture the prompt administration of antibiotics for pneumonia was

$104 \mathrm{Id}$. at 49,838 .

105 Judith H. Hibbard et al., An Experiment Shows That a WellDesigned Report on Costs and Quality Can Help Consumers Choose High-Value Health Care, 31 HEALTH AFF. 560, 565-66 (2012), available at http://content.healthaffairs.org/content/31/3/560.full.pdf+html [https:// perma.cc/FL3J-74HE] (showing also that altering presentation format and the quality signal provided could help address this problem).

106 Hospital Compare, MEDICARE.GOV, https://www.medicare.gov/ hospitalcompare/search.html [https://perma.cc/U88C-3N2V] (last visited May 26, 2016).

107 BEN-SHAHAR \& SCHNEIDER, supra note 4, at 176. 
revised after its time constraints put pressure on providers to supply antibiotics to patients whose diagnosis was not yet confirmed. 108

Quality reporting can also lead to gaming that can lower quality for patients and potentially exacerbate inequalities. One study found that when New York and Pennsylvania implemented their cardiac surgery reporting systems, the average severity of illness of patients receiving bypass surgery went down, suggesting that physicians were turning away sicker patients. 109 While the results indicated that sicker patients were more likely to be matched with teaching hospitals, the adoption of report cards was associated with poorer outcomes overall, including for sicker patients. ${ }^{110}$ Another study found that the release of New York's bypass surgery report card was associated with increased racial and ethnic disparities in the receipt of cardiac care. ${ }^{111}$ This could occur if physicians are concerned that members of racial or ethnic minority populations might be at a "higher risk for poor outcomes" in ways that quality metrics fail to capture, thus inappropriately worsening outcomes measures. ${ }^{112}$

Quality ratings could also increase disparities if one group is more likely to see, understand, and properly use quality ratings than another. For example, if more educated individuals have both better underlying health and a stronger tendency to use report cards well, then educationbased disparities may begin to increase. Note, however, that this kind of effect depends on both treatment patterns in the absence of report cards and on the identity of report card users. If the most educated patients already acquire quality information through other sources, then it may be less educated patients whose behavior is most impacted by report cards.

108 See Robert M. Wachter et al., Public Reporting of Antibiotic Timing in Patients with Pneumonia: Lessons from a Flawed Performance Measure, 149 ANNALS INTERNAL MED. 29, 29 (2008).

${ }^{109}$ Dranove et al., supra note 43 , at $570,582-84$.

${ }_{110} \mathrm{Id}$.

111 Rachel M. Werner, David A. Asch \& Daniel Polsky, Racial Profiling: The Unintended Consequences of Coronary Artery Bypass Graft Report Cards, 111 CIRCULATION 1257, 1257 (2005).

112 Id. 
There are plenty of reasons to believe that the costs discussed in this section are "real," and evidence points to the existence of some types of costs. Evidence is sparser for other types, however, and many of the costs are difficult to quantify, increasing the challenges of a full analysis of the net impact of reporting.

Note that even if studies show that these costs exist, there are ways to limit them. As electronic health records spread and improve, data collection costs should go down. Reporting refinements and other interventions can also reduce the costs of reporting. Researchers have identified ways to increase the likelihood that users understand the information presented. ${ }^{113}$ Gaming is always a possibility, but revising outcomes metrics to capture the risks that most concern physicians may reduce the opportunity for gaming. Thus, while using current evidence to assess costs is an important first step in analyzing the impact of reporting initiatives, it is also important to consider the likelihood of future changes that might affect those costs. The same observation could be made about an analysis of reporting's benefits.

\section{The Marginal Costs of Quality Reporting}

One other complication in evaluating the impact of quality reporting is that the infrastructure necessary to comply with government reporting mandates may yield other benefits. Many of the financial costs associated with reporting are not actually the costs of reporting; they are the costs of data collection and measurement. These costs could be viewed as an investment supporting a range of provider activities.

For example, a health care provider may want to track a variety of quality metrics in an effort to improve its own health care quality, without regard to the existence of any mandated reporting program. Third parties with an interest in monitoring quality may seek access to quality metrics, regardless of whether the metrics are also publicly reported. Private and public payers may choose to incorporate quality

113 See Hibbard, supra note 105 (discussing effects of changing report card and format). 
metrics into their payment formulas. ${ }^{114}$ If an accountable care organization must report a series of quality metrics in order to receive payments under the federal shared savings program, then the marginal financial costs associated with public reporting of the same metrics will be small. ${ }^{115}$ In the current environment, many provider organizations would face significant data collection and measurement costs even in the absence of a public reporting program. The marginal costs of a disclosure mandate would therefore be quite low, strengthening the justification for quality reporting requirements.

At the same time, however, the existence of these other uses of quality data might also affect the marginal benefits of a reporting mandate. If pay-for-performance payment regimes are effective mechanisms for ensuring quality, 116 then public reporting may not have much effect. Ultimately, in a world in which quality measurement is already underway, assessing whether a disclosure mandate is a "success" or "failure" requires a comparison between the marginal costs and the marginal benefits associated with adding a reporting requirement. The gains from reporting may be small, but if the marginal costs are smaller still, implementing the reporting mandate will have a positive net impact. If quality measurement is not yet underway, then the costs of implementing a measurement-based reporting regime should be compared not just to the benefits associated with reporting, but also to other benefits arising from the development of the underlying measurement infrastructure.

114 See Julia James, Health Policy Brief: Pay-for-Performance, HEALTH AFF. 1 (Oct. 11, 2012) (describing pay-for-performance programs).

115 See Dep't of Health \& Human Servs., Improving Quality of Care for Medicare Patients: Accountable Care Organizations (April 2014), https://www.cms.gov/Medicare/Medicare-Fee-for-Service-

Payment/sharedsavingsprogram/Downloads/ACO_Quality_Factsheet_IC N907407.pdf [https://perma.cc/6AUS-YR62] (describing quality metrics used as the basis for rewards in Medicare's Shared Savings Program and noting the alignment between the program and other quality reporting metrics).

116 See BeN-ShaHAR \& SCHNEIDER supra note 4 at 176 (describing results of studies of pay-for-performance programs). Like the studies on quality reporting, studies on the impact of pay-for-performance are mixed. 
The costs will almost certainly be large, but the gains may be as well. In short, an assessment of the net impact of reporting will depend not just on the attributes of the reporting mandate in question, but also on the nature of other quality-related initiatives already underway or soon to be adopted. These assessments will be challenging in an environment characterized by continuous reform; in such circumstances, longer-term gains will be much more difficult to evaluate than short-term costs.

\section{Alternatives to MANDATEd Disclosure}

Given the prevalence of mandated disclosure as a regulatory mechanism, it is natural to respond to a call to abandon the mechanism with a question about how best to replace it. Professors Ben-Shahar and Schneider dismiss the question, and with good reason, if their premise is correct. If mandated disclosure does nothing, or makes things worse, then nothing is lost if it is abandoned. 117 The only question to be asked in such a case is whether there is some other sort of regulation or other initiative that would actually achieve the goals of the mandated disclosure, at a reasonable cost. Ben-Shahar and Schneider do not explore this question in detail, as it is beyond the scope of their book, but they do discuss a few possibilities. ${ }^{118}$ This Part explores two possible alternatives to reporting mandates: voluntary reporting and direct regulation.

\section{A. Voluntary Reporting as an Alternative to Mandatory Quality Reporting}

Ben-Shahar and Schneider point out that there are often alternative sources of the kinds of information that reporting provides. Many organizations provide consumer information, including ratings, reviews and other muchwanted forms of advice that mandated disclosures may lack.119 Organizations that collect and disseminate

\footnotetext{
117 BEN-SHAHAR \& SCHNEIDER, supra note 4, at 183.

118 See id. at 183-95 (discussing alternatives to disclosure).

119 Id. at 185 .
} 
information abound, and they do not necessarily need to obtain information through mandates. ${ }^{120}$

As Ben-Shahar and Schneider suggest, it is true that private entities do not need publicly-reported health care quality data to create their own ratings. Consumers can obtain advice similar to what they would get from government report cards through a number of private organizations that supply quality information drawn directly from providers, from public claims databases, or from third parties. ${ }^{121}$ This reality, though, creates problems of its own. To the extent that organizations' measures are derived from data supplied directly by providers, private reporting programs have the potential to add to the burden faced by providers that might already be reporting on hundreds of measures for public reporting or payment purposes. ${ }^{122}$ Furthermore, a proliferation of quality metrics can also create considerable confusion for patients, who are confronted with many competing and sometimes contradictory quality metrics. ${ }^{123}$ In other words, a proliferation of voluntary reporting programs can create a sort of overload, just as an overly complex mandated disclosure can.

Professor Craswell notes the problems of inconsistent measurement systems, and suggests that mandatory disclosures might benefit users by making direct comparisons easier and reducing the burden consumers would otherwise face in trying to understand multiple

\footnotetext{
${ }^{120} I d$. at $187-88,190$.

121 See, e.g., 2015 Leapfrog Hospital Survey Results Now Available, THE LEAPFROG GROUP http://www.leapfroggroup.org/cp [https:// perma.cc/2YYX-YHNN] (last visited May 26, 2016) (reporting based on data supplied by hospitals); FAQ: How and Why We Rate Hospitals, U.S. NEWS \& WORLD REPORT (July 21, 2015, 12:01 AM), http:// health.usnews.com/health-news/best-hospitals/articles/2015/05/20/faqhow-and-why-we-rate-and-rank-hospitals?int=ab2909\&int=ad4609 [https://perma.cc/PE4N-34LJ] (describing hospital rating methodology involving physician surveys).

122 See, e.g., Massachusetts Health Policy Commission, 2014 Cost TRENDS REPORT 59 (2014) (finding that Massachusetts providers reported more than 400 quality measures to different entities).

123 Michael B. Rothberg et al., Choosing the Best Hospital: The Limitations of Public Quality Reporting, 27 HEALTH AFF. 1680, 1686 (2008).
} 
metrics. ${ }^{124}$ Federal reporting websites do this to at least to some extent by providing information on a very large number of providers for a very broad range of services, and ensuring at least some consistency in the presentation of information. The federal government's purchasing power ensures that it has access to a broad range of provider data. By contrast, other quality-related websites may include only a subset of providers, or exist for only a particular type of care.

It may be possible to achieve consistency in reporting through collaboration across entities, rather than by governmental mandate. Recently, the Center for Medicare and Medicaid Services worked with major commercial health plans and others to increase the alignment across measures used for a variety of quality programs. ${ }^{125}$ However, even if such multistakeholder groups exist, the government's leadership role in reporting initiatives may help to accelerate the process of reaching a voluntary agreement.

Craswell highlights one more important effect of a governmental mandate: he suggests that "when the government requires the disclosure of information, that decision itself signals to (some) consumers that the issue is important enough to worry about, thus making sellers' later voluntary disclosures more salient to consumers." 126 It is possible that this is the case for health care quality. By making data available to the public for free and publicizing its availability, policy makers may increase the public's focus on health care quality.

For all of these reasons, mandatory reporting may yield gains that purely voluntary reporting programs might struggle to achieve. It is also the case that existing mandatory reporting regimes possess some of the attributes

${ }^{124}$ Craswell, supra note 22, at 368.

125 Press Release, CMS and Major Commercial Health Plans, in Concert with Physician Groups and Other Stakeholders, Announce Alignment and Simplification of Quality Measures (Feb. 16, 2016), https://www.cms.gov/Newsroom/MediaReleaseDatabase/Press-releases/ 2016-Press-releases-items/2016-02-16.html [https://perma.cc/M7TKPDUE]; Patrick H. Conway and the Core Quality Measures Collaborative Workgroup, The Core Quality Measures Collaborative: A Rationale and Framework for Public-Private Quality Measure Alignment, HeALth AFF. BLOG (June 23, 2015).

${ }^{126}$ Craswell, supra note 22 , at 368. 
that Ben-Shahar and Schneider look for in alternative reporting mechanisms. For example, publicly-produced quality reporting would seem to fall in the category of "advice" that Ben-Shahar and Schneider describe. Furthermore, while other types of mandated disclosure may "rarely teach" "how businesses actually behave," 127 quality report cards attempt to characterize actual behavior. In short, while a variety of information provision mechanisms might perform some key functions of reporting mandates, today's quality reporting mechanisms offer important benefits for information users.

\section{B. Direct Regulation as an Alternative to Mandatory Quality Reporting}

Ben-Shahar and Schneider also note that in some cases, more paternalistic forms of regulation might be a viable alternative to reporting mandates. ${ }^{128}$ If policy makers believe that having more nurses may help achieve higher quality of care, but are convinced by Ben-Shahar and Schneider that a nurse staffing ratio report card will fail as a policy intervention, then perhaps they could regulate directly by mandating staffing ratios. The translation of some quality metrics, such as mortality rates, to command-and-control regulations is more challenging than the staffing ratio example implies, but in theory government regulators could become more active in mandating practices that have been found to reduce mortality.

Many people would view this kind of intervention as problematic on the grounds that it involves too much interference with the ever-changing practice of medicine. Command-and-control regulation can forestall innovation and impose inappropriate or unnecessarily costly practices on providers. Structural and process-based quality reporting measures allow for variation, even while pushing providers toward a particular standard; outcome-based metrics such as adjusted mortality rates provide flexibility to providers in how they seek to achieve better outcomes. A desire for flexibility is no reason to advocate for reporting that does not

127 Id. at 188.

${ }^{128} I d$. at 194 . 
work, but flexibility can help avoid some of the risks of command-and-control regulation.

Note too that command-and-control regulations are subject to many of the criticisms lodged against mandated disclosure, a point emphasized by Professor Craswell.129 Nurse staffing mandates, like nurse staffing reporting requirements, could undermine quality if the metrics used are not actually associated with quality. A nurse staffing mandate pulls resources away from other areas in need of attention, possibly including areas that matter more for quality. A requirement for nurse staffing levels may lead to gaming that helps providers meet the requirement without improving outcomes.

Authors of a recent article that compares evidence on quality reporting with evidence on direct quality regulation argue that both approaches can "induce teaching to the test" and "be subject to cream skimming," and then state that "[a]lthough very few efforts have been made to measure the costs of these approaches, regulation, when enforced, is almost certainly more costly." 130 This conclusion points to the advantages of reporting, but the authors' ultimate conclusion points in a different direction. While one of the authors' objectives was "to compare the effectiveness and cost-effectiveness of regulation and report cards in improving quality," they conclude that "such a comparison is not yet feasible," partly because studies evaluating the policy tools "use different metrics to measure their effects," partly because they address different sectors, and partly "because of the dearth of cost studies." 131

129 See Craswell, supra note 22, at 367. At the same time, disclosure mandates can share some of the shortcomings of command-and-control regulation. Professor Ryan Bubb suggests that some disclosure mandates may be intended to manipulate consumer choice, rather than merely attempting to debias faulty consumer decision making, and "should be subjected to cost-benefit analysis in much the same way as are more transparently coercive tools like product regulation." Ryan Bubb, TMI? Why the Optimal Architecture of Disclosure Remains TBD, 113 MICH. L. REV. 1021, 1039 (2015).

130 See Mukamel et al., supra note 81, at 492.

131 See id. 


\section{CONCLUSION}

The challenges of comprehensively evaluating the effects of policy interventions give room both to claims that disclosure mandates have failed, and to claims that they might succeed. While the evidence discussed in Part II.C makes clear that mandated quality reporting has the potential to succeed, Part III's evidence on costs is much sparser. It is certainly possible that reporting's costs exceed its benefits. On the other hand, it is also possible that gains exceed costs for at least some subset of current quality reporting initiatives. I lean toward this latter conclusion, in part because I believe that quality reporting has done a lot to focus providers' attention on quality issues, and in part because of the long-term benefits that investments in the infrastructure supporting quality reporting can yield. Whatever may be true right now, I believe that it is likely that future versions of today's mandates will fare better in a cost-benefit analysis, both because I anticipate that reporting systems will be revised in light of emerging research about what works and what does not, and because I believe that the marginal costs of quality reporting will decline over time.

I suspect that similar observations could be made for other forms of mandated disclosure, but I am not sure how much can be extrapolated from this essay's analysis of quality reporting. It would not be unreasonable to view quality reporting as a sui generis form of disclosure mandate. It differs from other disclosure mechanisms in multiple ways. For example, the primary end goal of quality reporting does not seem to be fully informed consumers, but instead higher quality care; in other words, the ultimate aim is not to support patient (consumer) choice in a world with diverse products, but instead to ensure that the product delivered has a particular attribute. While many of the mandates Professors Ben-Shahar and Schneider consider involve the direct provision of information from a business to a consumer, health care quality reporting typically involves health care providers' provision of information to a government entity, which then makes information available to consumers. For many people, health care quality likely matters more than the specific details of privacy policies, or boilerplate contract terms that govern disputes that rarely 
arise. Quality report cards seem much more straightforward to understand than a mortgage. The fact that providers may find quality measurement useful for multiple purposes means that quality reporting processes may be intertwined with provider operations in ways that other kinds of disclosures meant to clarify product characteristics, such as term sheets, are not. 132

This brief list of some of the ways that health care quality reporting differs from other mandates makes clear that there are many dimensions along which disclosure mandates may differ. They differ in their goals and the mechanisms by which they seek to achieve them. ${ }^{133}$ They differ in their degree of salience to their audiences. ${ }^{134}$ They differ in complexity. They differ in costs, financial and otherwise, and they may differ in who bears these costs. They may also differ in the extent to which alternative regulatory mechanisms could achieve their goals. 135 The sheer diversity of disclosure mandates raises the possibility that some disclosures will succeed while others fail; even Ben-Shahar and Schneider leave open the possibility that at least some mandates succeed. If we could develop a framework that systematically lays out the key characteristics of disclosure mandates and the environments in which they operate, then

132 Provider quality reporting mandates may also differ from other disclosure regimes in that they often take the form of "pay for reporting" initiatives, rather than statutory or regulatory requirements to report. See, e.g., Home Health Quality Reporting Requirements, CMS.GOV, https://www.cms.gov/Medicare/Quality-Initiatives-Patient-AssessmentInstruments/HomeHealthQualityInits/Home-Health-Quality-ReportingRequirements.html [http://perma.cc/PQM6-9G5F] (last modified 10/29/2015 3:25 PM) (noting that federal statute requires home health agencies to submit data, describing the financial consequences if home health agencies do not submit data, and describing the requirement as a "pay-for-reporting" requirement).

${ }_{133}$ Professor Bubb offers a thoughtful discussion of the implications of disclosure mandates that seek to debias versus mandates that seek to manipulate behavior. Bubb, supra note 129, at 1028-1039.

134 See Mukamel et al., supra note 81, at 492 (noting that the risk of delayed treatment for pneumonia "may not be significant to enough potential patients to make report card effective; therefore, direct regulation may be a more appropriate approach than a report card").

${ }^{135} \mathrm{Cf}$. id. (Observing that reporting "is considered an attractive policy instrument in an area where surgeon skill is very important and probably difficult to regulate"). 
we may be able to better predict disclosure mandate success - and increase it.

The utility of such a framework will necessarily depend on the quality of data that underlies it. Evaluating the success of existing mandates requires careful consideration of both benefits and costs. As Professor Bubb has observed, "[t]he right response to the important critiques of mandatory disclosure that Ben-Shahar and Schneider raise is . . . rigorous empirical assessment of which disclosures work and which do not, with an eye toward the pitfalls the authors document." 136 Moreover, as Professor Craswell emphasizes, it will be important to define criteria for success, which will in turn depend on the nature of the goals policy makers seek to achieve. 137

More Than You Wanted to Know conveys an important warning: disclosure mandates rarely fulfill their advocates' hopes, and the reasons that disclosure mandates disappoint are not easily addressed. This essay demonstrates, however, that some disclosure-based policy strategies have a reasonable chance of succeeding. With more data, more analysis, and a clear articulation of policy goals, we can determine whether they actually do.

136 Bubb, supra note 127, at 1023.

137 See Craswell, supra note 22, at 337-40 (on goals); see also id. at 380 (calling for development of criteria for success). 